\title{
Health Impact of Climate Change in Bangladesh: A Summary
}

\author{
Enamul Hasib1, Prita Chathoth ${ }^{2}$ \\ ${ }^{1}$ Continuing Education Programme, James P. Grant School of Public Health, BRAC University, Dhaka, \\ Bangladesh \\ ${ }^{2}$ Climate Change \& Health, Virginia, USA \\ Email: enam.hasib@bracu.ac.bd, prita.chathoth@gmail.com
}

Received 28 December 2015; accepted 2 February 2016; published 5 February 2016

Copyright (C) 2016 by authors and Scientific Research Publishing Inc.

This work is licensed under the Creative Commons Attribution International License (CC BY). http://creativecommons.org/licenses/by/4.0/

(c) () D Den Access

\section{Abstract}

Bangladesh, one of the South Asian countries, has started experiencing major public health impacts of climate change due to its vulnerable geographical location. The objective of this paper is to look at the extent of climate change in Bangladesh and its impact on human health. This paper is based on the review of relevant literature and journal articles on climate change and health from varied recourses. Major health impacts of climate change in Bangladesh observed are temperature related illness, food, water and vector borne diseases. About 20 million people in more than 27 districts are at risk of having Leishmaniasis. Human health is at serious risk due to climate change in Bangladesh though the country's contribution to Greenhouse Gas emissions is very small compared to many developed nations. Unless steps are taken and put in place immediately to mitigate and adapt to climate change, Bangladesh will have to pay a heavy toll in terms of productivity and human lives.

\section{Keywords}

\section{Climate Change, Health Impact, Infectious Disease}

\section{Introduction}

Climate change has already established its impression through various recent extreme climatic events around the world such as recent prolonged and devastating floods in Bangladesh, India, China and the UK, severe drought in Asia and Africa, extreme heat waves in central Europe, devastating cyclones and tidal surges across the coasts. It is the direct result of the burning of fossil fuel and wasteful consumption by the people in industrialized and rich countries. An increase in the frequency and intensity of extremes of temperature, precipitation and wind 
speed has clear implications for mortality and morbidity (Nerlander, 2009). Climate change leads to deaths of at least 150,000 people around the world every year and the figure is likely to increase. Children, the elderly, and those in disadvantaged communities are the most vulnerable to this exacerbation. In many respect, the developing countries are particularly susceptible to climate-related health impacts. According to Woodward et al., (1998: p. 32) the low-lying coastal countries of Asia are more liable to damage than other countries from rising sea levels. The global climate change may affect human health both directly and indirectly (Shahid, 2009: p. 312). The direct effects include injury and illness due to the more frequent heat waves and floods-expected as a result of higher temperatures, extremes of rainfall and thermal expansion of the oceans. The indirect effects are more difficult to specify, but will probably be more important in terms of the magnitude of the disease burden they cause. These will be the disruption of natural system, causing infectious disease, malnutrition, food and water-borne illness, and increased air pollution (Patz et al., 2005: p. 311). The vulnerability of societies to climate change will therefore depend on the ways in which critical ecosystems adapt to climatic change (Martens et al., 1997).

Bangladesh is a South Asian country with a total population of about 160 million, and is one of the most densely populated countries in the world. Most part of the country is low-lying and floodplains occupy $80 \%$ of the country (Islam, 2008). About $80 \%$ of the people live in rural areas although there is rapid urbanization. Agriculture, manufacturing, transport, trade etc. make up the major economic sectors of the country. Bangladesh has humid, warm, tropical climate, influenced primarily by monsoons. The monsoon season starts around the first week of June and lasts until the first week of October. The easterly trade winds provide warm and relatively drier circulation. There are four distinctive seasons: winter (December to February), pre-monsoon (March to May), monsoon (June to early October), and post-monsoon (late October to November). It has moderately warm temperatures and high humidity with heavy torrential rains throughout the monsoon season. Annual rainfall ranges from $1200 \mathrm{~mm}$ in the west to more than $5000 \mathrm{~mm}$ in the east and north-east. 23\% of the country is covered by coastal zone with a 710-kilometer long coastline (Islam, 2008). Bangladesh is one of the most disasterprone countries in the world Due to its geographic location. As Agarwala et al. (2003: p. 6) described climate change poses significant risks for Bangladesh, yet the core elements of its vulnerability are primarily contextual. A major storm event may result in approximately 290 DALY per 1000 population, including both deaths and injuries, compared to a current all-cause rate of about 280 per 1000 in the region (Nelson, 2003: p. 323). This review has been undertaken to briefly describe the major routes through which climate change impacts Health. The objective of this paper is to understand the extent of climate change in Bangladesh and its impact on human health.

\section{Methodology}

This systematic review involved assessing the impacts of climate change on the health of the people of Bangladesh. To find suitable articles multiple databases were chosen. These were Lancet, CINAHL, EMBASE, MEDLINE, British Nursing Index, DH-DATA. These databases were accessed through Hinari and Dialog Datastar, the electronic gateway used at the University of Wolverhampton. At first CINAHL was selected for advanced search. "Climate change" was included for thesaurus mapping for information up to last 10 years from the time of search. After clicking "search" we got descriptors for climate change. Then we clicked all major descriptors for climate change and click "search" and got a search history.

We repeated the same procedure with other keywords such as, health, impact, Bangladesh, vulnerability. Finally, we combined all these search history and got the result of 40 articles. The language of all those articles was English.

Removing duplicate articles the number reduced to 28. The whole procedure was done with the rest of the selected databases. We found 34 articles for EMBASE, 42 articles for MEDLINE, 36 for Lancet. Duplicate articles were removed selecting all databases and unique ones combined in a single list. As shown in Figure 1, we found 118 unique articles in a list of combined databases. Our next step was to exclude articles that did not meet inclusion criteria (review articles, letters, focused on countries other than Bangladesh). 90 papers excluded and the count came down to 28. Apart from these we also searched 50 abstracts out of which 39 excluded as those did not match inclusion criteria. Finally, (full paper of 11 abstracts and 28 other papers) 39 appropriate papers were obtained. We searched manually as well. International and local websites of environment and climate change were examined. During manual search we found some articles in the reference list of other articles. In this way, we found another 5 articles which made the total of 44 articles. 


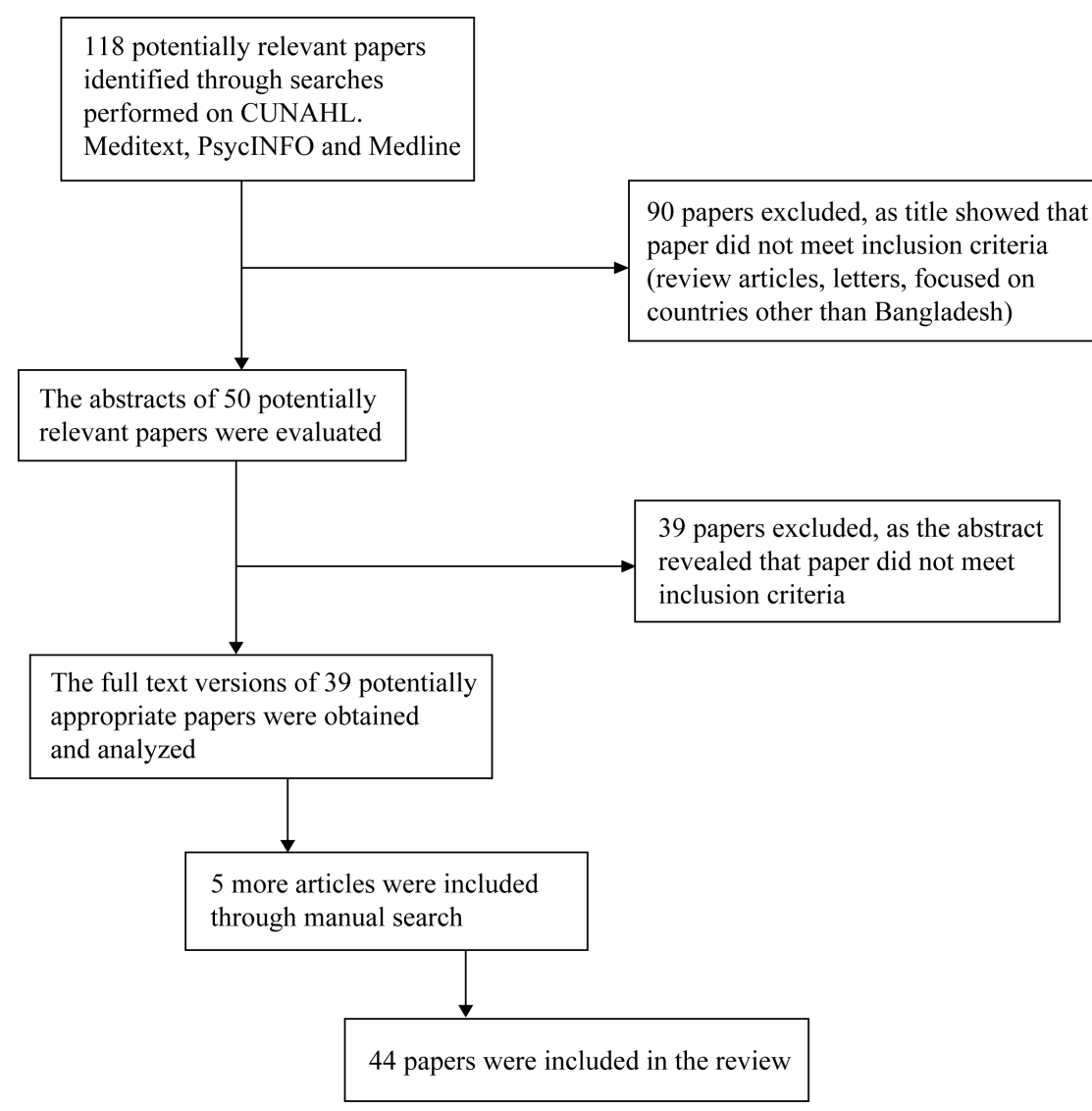

Figure 1. Process of selection of studies for inclusion in the review.

Some difficulties faced during the individual search. Online sources included abstract and other descriptions such as the period of publish, author's name and name of the journal but the full article. Most of the cases, articles were not freely accessible. Another major problem encountered during literature search was finding articles about Bangladesh. Either sufficient research on climate change has not been done or only a few works are available in electronic resource. Finally all the articles were checked individually. All articles those did not correlate climate change and health impacts had been excluded. The main criteria for including articles were the health impact of climate change on the population of Bangladesh. In order to evaluate recent knowledge, articles published before the year 2000 (older than ten years) were not included.

\section{Results and Discussion}

The findings in terms of incidence of disease, geographical distribution and role of climate change as a catalyst factor have been discussed separately for each of the General Health Impacts; Infectious Diseases; Food Security and Nutrition; and Air Pollution.

\section{General Health Impacts}

Costello et al. (2009: p. 1700) illustrated how climate change and its rapid emergence in the past decades can be a major challenge to public health together with poverty, inequity, and infectious and non-communicable diseases. Furthermore, the poorest countries will suffer the greatest consequences of climate change even though they contributed the least for emissions. Climate change has altered the distribution of some infectious disease vectors and some allergenic pollen species (IPCC 2007). Climate plays an important role in the seasonal pattern or temporal distribution of malaria, dengue, tick-borne diseases, cholera and other diarrhoeal diseases. World Health Organization (2003) carried out a comparative risk assessment study at regional and global levels to quantify the amount of premature morbidity and mortality due to risk factors including climate change. The 
study found that in 2000, climate change have caused loss of over 160,000 lives annually (Campbell-Lendrum et al., 2003; Ezzati et al., 2004; McMichael, 2004). The health outcomes due to the effects of climate change included: episodes of diarrhoeal disease; cases of Plasmodium falciparum malaria, fatal accidental injuries due to floods and landslides; and malnutrition. Green (2006: p. 8) mentioned that an increase in extreme events are likely to cause larger number of injuries and accidental death. She continued that three Torres Strait Islanders were caught at sea for 22 days in the wake of Cyclone Monica, one of the most intense tropical cyclones ever recorded in Australia, which passed by the Torres Strait in April 2006. The combination of higher temperatures and potential increases in precipitation could create the conditions for greater intensity or spread of many infectious diseases (Mirza, 2003: p. 243). The adverse health impacts will be the greatest in low income countries targeting the urban poor, the elderly and children, traditional societies, subsistence farmers and coastal populations. The direct and indirect impacts of climate change cited above can cause death, disability and suffering.

\section{Infectious Diseases}

Dengue, the world's most important vector-borne viral disease, was not prevalent in Bangladesh until 2000 (World Health Organization, 2008). Since then, the disease became predominantly endemic in urban areas. The incidence of dengue occurs every year in Bangladesh, especially Dhaka causesa constant threat to the population and is a recurring problem for the health authorities. Furthermore, all environmental conditions that can trigger an outbreak are more or less present (Rahman, 2008: p. 18).

The transmission session starts in June-July every year with seasonal fluctuation. A seasonal peak is observed in July when the temperature is in the higher side with a peak in the scale of humidity followed by a sharp decrease from September (Choudhury et al., 2008: p. 31). As of 2004, a total of 16,388 dengue cases have been reported. Most of these cases are confined to three major cities—Dhaka, Chittagong, and Khulna—with the highest incidence in Dhaka. In 2007 altogether 466 cases were reported. Maximum number of cases reported in August/September 2007 and 2008. The case fatality rate 0.5 in 2006 and there is no death in 2007 and 2008.

Leishmaniasis, locally known as kala-azar, has re-emerged as one of the major vector-borne diseases in Bangladesh since mid-nineties. It is estimated that about 20 million people in more than 27 districts are at risk (Bern \& Chowdhury, 2006: pp. 276-277). A total of 73,467 kala-azar cases were reported to the Malaria and Vector-Borne Disease Control Unit of Directorate General of Health Services (DGHS), Government of Bangladesh from 1994 through 2004. Bern \& Chowdhury also informed that annual kala-azar case total ranged from 3,965 to 8920 during the period of 1994 to 2004. Pabna district reported the highest annual number of kala-azar cases. After 1996, the incidence in Mymensingh overtook that in Pabna, and has continued to rise since that time. Every year from 2000 to 2004, Mymensingh accounted for more than 50 per cent of the total kala-azar cases reported in Bangladesh. Nevertheless, recent surveillance data indicated that the area of potential risk for visceral leishmaniasis is stretched from Noakhali and Patuakhali to Chittagong and the border with Bern \& Chowdhury, 2006: pp. 276-277.

Malaria has been in the epicentre of diseases linked to climate change. Malaria is not equally distributed in all malaria endemic districts of Bangladesh. Out of 64 districts, 13 bordering districts in the east and northeast are considered as high risk zone. A total of 14.7 million populations are at high-risk of malaria (WHO, 2010). Prevalence of malaria in 5 south-eastern districts is significantly higher than the 8 north-eastern districts. Chittagong Hill Tracts districts have the highest prevalence than the other endemic districts (Ahmed et al., 2008: p. 33). A study conducted in four sub districts of Bangladesh by Maude et al. (2008: p. 89) found Malaria API as 8.4/1,000/year. This gives an overall estimate that total malaria cases in high transmission areas are three times higher than the reported number for the whole country in 2006.

Malaria exists in Raumari, Sreebardi, Haluaghat, Chunarughat and Kanaighat Thanas in Kurigram, Sherpur, Mymensingh, Habigong and Sylhet districts respectively. Malaria is also prevalent in Maulovibazar district. Maheshkhali, Chakaria, Ukhia Thanas in Cox’s Bazar district and Fatikchari, Mirasarai, Rangunia and SatkaniaThanas in Chittagong district have elevated prevalence rate. All Thanas of Chittagong Hill Tracts districts have very high prevalence of malaria (Ahmed et al., 2008: p. 33). Data from 2001 to 2005 show a marked increase in the incidence of malaria.

Flooding of rivers increase possibility of communicable diseases by ingesting contaminated water and contact with flood waters. Outbreak of Diarrhoea occurs almost every year in Bangladesh during summer and after flood. In Bangladesh, watery diarrhoea in a population displaced by floods is the most common cause of death for age 
group under 45. Settlement of populations in high risk areas such as floodplains and river deltas increases vulnerability. World Bank (2006) suggests that the diarrhoeal disease caused by inadequate access to safe water, lack of sanitation and poor hygiene may contribute up to $10 \%$ of the total burden of disease. Diarrhoeal diseases have also seen an increase in recent years, although current treatment strategies have reduced mortality considerably.

\section{Food Security and Nutrition}

Extreme climatic events causing decreased food production and inadequate supply affect health, education, child nutrition and income sources of the households. With rising food prices, dietary diversity, quality, and quantity decline placing vulnerable populations at increased risk of malnutrition. Rice prices are known to be positively associated with the prevalence of child underweight. Household spends more on non-rice foods and less on rice has a lower prevalence of maternal and child malnutrition and vice versa (Bloem et al., 2009: p. 133). When food prices increase, per capita rice consumption does not change, but there is a proportionate increase in rice expenditure while less money is spent on non-rice foods. This unsustainable coping strategy resulting reduced quantity of dietary intake causes an increase in micronutrient malnutrition. The aftermath of this follow them into adulthood in the form of poorer health, lower incomes, and reduced physical and intellectual capabilities. Decades of research have increasingly combined evidence of the pervasive impact of food and nutrition insecurity among at-risk population groups such as infants and young children, pregnant and lactating women, and the chronically ill resulting from acute and chronic crises (Bloem et al., 2009: p. 135).

In Bangladesh different studies on nutritional status showed that the percentage of stunted and underweight children in rural areas is significantly higher compared to children in urban areas (45\% compared with 36\%). At the national level, $51 \%$ of children under the age of five years are stunted, $56 \%$ underweight and $14.7 \%$ are wasted by international standards. Per capita dietary energy supply in Bangladesh shows a declining trend. In Bangladesh, moderate and severe malnutrition remains a major public health problem. Gender differences in nutritional status existed in the past seems to have disappeared. The percentage of stunted and underweight children is higher in households with lower per capita annual expenditure. There is a significant variation among the stunted and underweight children based on diversity of geographical area. Out of the five administrative divisions in the country, Barisal which is a coastal area has the highest percentage of malnourished children while its neighboring division, Khulna has the lowest percentage. Another study (Mojumder \& Khuda, 2000: p. 291) showed that about one-third of infants and young children are moderately malnourished. The proportion of malnourished children is increased with the number of older surviving children. In Bangladesh, children are at higher risk of malnutrition if they are female, their mothers are less educated, they have several siblings, and either previous or subsequent siblings were born within 24 months (Mojumder \& Khuda, 2000: p. 289).

\section{Air Pollution}

Despite low level of $\mathrm{CO}_{2}$ emissions (0.3 tonnes per capita according to World Bank, 2009), outdoor air pollution is a major environmental threat to Bangladesh, especially in urban areas (Islam, 2009: p. 11). Lead poisoning is likely to be a major public health problem in Bangladesh. Islam (2009: p. 12) also informed that several industries including ceramic factories, battery production and processing factories, plastic manufacturing industries, chemical and pharmaceutical industries, cement production and processing factories, fertilizer factories, metal workshops, and car repair and welding workshops are good sources of lead in the major cities in Bangladesh. In a cross-sectional study of 779 school children in the city of Dhaka, nearly $90 \%$ had BLLs more than $10 \mu \mathrm{g} / \mathrm{dL}$ possibly due to environmental exposure from gasoline, paints, ceramics, and used batteries (Mitra et al., 2009). The respiratory infections and disease caused by poor air quality, both indoor and urban, may contribute up to $10 \%$ of the total burden of disease (World Bank, 2007; World Bank, 2006).

An overall, often overlooked impact on human health is heat related stress. This is all the more pronounced in outdoor manual-labourers such as transport and construction workers who have to work long hours in intense heat. This can result in health related complications such as heat stroke and dehydration and so on.

\section{Public Health Response and Adaptation Measures}

Although Bangladesh is virtually zero contributor to the greenhouse gas emissions that affect global climate 
change, it is ironic that it has to suffer so disastrously from the effects of climate change that are likely to occur in the coming decades (Ali, 1999: p. 114). Keeping this in mind, the government of Bangladesh has made climate change an integral part of its national development strategy and have started to develop the country's capacity to deal with the impacts of climate change. Adaptation activities should involve the full range of stakeholders including community leaders, health professionals, local government, private organizations, and NGOs. Climate Change Strategy and Action Plan (CCSAP) have been developed by the government in consultation with all development partners and stakeholders. Food security and health are two most important pillars of CCSAP. Several initiatives have been taken by the DGHS (Directorate General of Health Services) to develop National Guidelines for health, to control Dengue and DHF. A National Guideline for treatment of malaria has also been introduced. It focuses on disease control and endorses early diagnosis, prompt treatment, recognition of treatment failures and management of severe and complicated cases in hospitals. Malaria surveillance, preparedness for control of malaria outbreaks and introduction of insecticide impregnated mosquito nets are also in place (NAPA, GoB, 2005). An emergency plan for controlling Leishmaniasis (kala-azar) was initiated in 19941995 in 11 districts with a total population of five million. Treatment of diarrhoeal diseases has been made more effective and efficient through proper supply and use of Oral Re-hydration Solution. There is no "safe limit" of climate change with respect to health impacts (Kovats et al., 2005: p. 1416).

\section{Conclusion}

Rapid urbanization along with poor sanitation, inadequate waste management, deforestation and fuel burning is increasing the risk of heat, flood, cyclones, earthquakes and sea level rise. The ultimate result is loss of lives and livelihoods, massive migration, increased vector borne diseases, malnutrition and psychological stress. Inadequate public health infrastructure is a major challenge for Bangladesh, especially in vulnerable areas. Measures should be taken to cope with the inevitable changes including construction of floodwalls, development of drought tolerant crops, adoption of irrigation methods that use less water, ensuring no settlements in vulnerable areas. Better urban design and planning measures have to be put in place to reduce urban crowding and reduce exposures. There are many possible co-benefits in implementing adaptation measures. Such as, by putting in place the measure for controlling diarrhoeal diseases, safe water supply and sanitation facilities will also help in the control of other water borne diseases such as Typhoid and Hepatitis A. There will be an overall reduction in mortality and morbidity of the general population. Reforestation to mitigate effects of climate change will prevent soil erosion and improve air quality. Hospitals and schools built in coastal areas may be used as flood shelters thus will enhance the quality of life for vulnerable populations. Improved urban management, including better housing design and zoning measures will result in enhanced quality of life and will create a less-polluted environment. Adaptation measures will be more effective with strong community participation.

Mitigation strategies need to be developed to reduce the impact of climate change through new policies, innovative technologies and a new life style. Introduction and use of renewable energy for industry and household use should be considered. Solar energy is a viable option for Bangladesh as the country is blessed with plenty of sunlight. Conservation of water sources and rainwater harvesting will benefit many sectors. River-encroachment and river-grabbing should be stopped by enforcing strict policies. Urban zoning laws can help reduce overcrowded pockets in larger cities, especially in Dhaka. Building and developing better facilities in rural areas will help prevent human migration to cities. Community-based solutions should be developed and implemented to make sure that people have a say in decisions affecting their well-being. Such approaches should also include various stakeholders and development partners from different sectors such as health, agriculture, environment, water resources and urban planning. It should also encourage public-private partnerships to monitor change, assess impact, facilitate adaptation and develop programs in order to face the challenge of climate change and develop holistic solutions. Climate change is not only an economic issue but also essentially a health issue. It has profound implications for public health. Health must be at the centre-stage of any climate change related adaptation plans. Moreover extensive and vigorous research is needed to better understand the link between climate change and health. Unless steps are taken and put in place immediately to mitigate and adapt to climate change, Bangladesh will have to pay a heavy toll in terms of productivity and human lives.

\section{References}

Agarwala, S., Ota, T., Ahmed, A. U. et al. (2003). Development and Climate Change in Bangladesh: Focus on Costal Flood- 
ing and the Sundrabans. Organization for Economic Co-Operation and Development. www.oecd.org/dataoecd/46/55/21055658.pdf

Ahmed, S., Islam, M. A., Haque, R. et al. (2008). Malaria Baseline Socioeconomic and Prevalence Survey 2007. BRAC$R E D, 10,32-33$. www.bracresearch.org/.../Malaria_Baseline_Survey_2007.pdf

Ali, A. (1999). Climate Change Impacts and Adaptation Assessment in Bangladesh. Climate Research, 12, 109-116. http://www.ingentaconnect.com/content/els/01959255/2003/00000023/00000003/art00102\%20 http://dx.doi.org/10.3354/cr012109

Bern, C., \& Chowdhury, R. (2006). The Epidemiology of Visceral Leishmaniasis in Bangladesh: Prospects for Improved Control. Indian Journal of Medical Research, 123, 275-288. http://icmr.nic.in/ijmr/2006/march/0309.pdf

Bloem, M. W., Semba, R. D., Kraemer, K. et al. (2009). An Introduction to the Impact of Climate Change, the Economic Crisis, and the Increase in the Food Prices on Malnutrition. The Journal of Nutrition, 140, 132-135.

http://jn.nutrition.org/cgi/content/abstract/140/1/132S

http://dx.doi.org/10.3945/jn.109.112094

Costello, A., Abbas, M., Allen, A. et al. (2009). Managing the Health Effects of Climate Change. Lancet, 373, 1702-1705, 1709-1710. www.ucl.ac.uk/global-health/ucl-lancet-climate-change.pdf http://dx.doi.org/10.1016/s0140-6736(09)60935-1

Green, D. (2006). Climate Change and Health: Impacts on Remote Indigenous Communities in Northern Australia. Commonwealth Scientific and Industrial Research Organisation, 6-9. www.sharingknowledge.net.au/files/indigenoushealth_cc200606.pdf

Islam, A. (2009). Climate Change and Health: Challenges for the Health System in Bangladesh. 11-14.

Islam, M. A. (2008). Climate Change and Development Risk: Local Perspective. The Daily Star, Bangladesh. www.thedailystar.net/story.php?nid=27722

Kovats, R. S., Campbell-Lendrum, D., \& Matthies, F. (2005). Climate Change and Human Health: Estimating Avoidable Deaths and Disease. Society for Risk Analysis, 25, 1409-1418.

http://veg.sage.wisc.edu/ zaks/sho/PDFs/Kovats\%202005\%20Climate\%20change\%20future\%20health\%20risk.pdf http://dx.doi.org/10.1111/j.1539-6924.2005.00688.x

Martens, W., Jetten, T.m \& Fock, D. (1997). Sensitivity of Malaria, Schistosomiasis and Dengue to Global Warming. Climatic Change, 35, 146-156. http://dx.doi.org/10.1023/A:1005365413932

Maude, R. J., Dondorp, A. M., Faiz, M. A. et al. (2008). Malaria in Southeast Bangladesh: A Descriptive Study. Bangladesh Medical Research Council Bulletin, 34, 87-89.

Mirza, M. M. Q. (2003). Climate Change and Extreme Weather Events: Can Developing Countries Adapt? Climate Policy, 233-248.

http://research.fit.edu/sealevelriselibrary/documents/doc_mgr/470/Global_Developing_Countries_\&_Extreme_Weather_Mirza_2003.pdf http://dx.doi.org/10.3763/cpol.2003.0330

Mitra, A. K., Haque, A., Islam, M., Bashar, S. A. M. K. et al. (2009). Lead Poisoning: An Alarming Public Health Problem in Bangladesh. International Journal of Environmental Research and Public Health, 6, 84-95. http://dx.doi.org/10.3390/ijerph6010084

Mojumder, A. B. M. K. A., \& Khuda, B. (2000). The Effect of Birth Interval on Malnutrition in Bangladeshi Infants and Young Children. Journal of Biosocial Science, 32, 289-300.

http://journals.cambridge.org/action/displayAbstract?fromPage=online\&aid=53057 http://dx.doi.org/10.1017/S0021932000002893

NAPA, GoB (2005). Ministry of Environment and Forest, Government of Bangladesh. National Adaptation Programme of Action (NAPA). http://unfccc.int/resource/docs/napa/ban01.pdf

Nelson, D. I. (2003). Health Impact Assessment of Climate Change in Bangladesh. Environmental Impact Assessment Review, 23, 323-341. http://www.ingentaconnect.com/content/els/01959255/2003/00000023/00000003/art00102 http://dx.doi.org/10.1016/S0195-9255(02)00102-6

Nerlander, L. (2009). Climate Change and Health. The Commission on Climate Change and Development, 10, 5-18. www.ccdcommission.org/Filer/commissioners/Health.pdf

Patz, J. A., Campbell-Lendrum, D., Holloway, T. et al. (2005). Impact of Regional Climate Change on Human Health. Nature, 438, 310-317. http://www.nature.com/nature/journal/v438/n7066/abs/nature04188.html http://dx.doi.org/10.1038/nature04188

Rahman, A. (2008). Climate Change and Its Impact on Health in Bangladesh. Regional Health Forum, 12, 16-26. www.searo.who.int/LinkFiles/Regional_Health_Forum_Volume_12_No_1_Climate_change_and_its_impact.pdf 
Shahid, S. (2009). Probable Impacts of Climate Change on Public Health in Bangladesh. Asia Pacific Journal of Public Health, 22, 310-319. http://aph.sagepub.com/cgi/rapidpdf/1010539509335499v1 http://dx.doi.org/10.1177/1010539509335499

Woodward, A., Hales, S., \& Weinstein, P. (1998). Climate Change and Human Health in the Asia Pacific Region: Who Will Be Most Vulnerable? Climatic Change, 11, 31-38. http://www.int-res.com/articles/cr/11/c011p031.pdf http://dx.doi.org/10.3354/cr011031

World Health Organization (2003). Climate Change and Human Health: Risks and Responses.

World Health Organization (2008). Climate Dengue Status in South East Asia Region: An Epidemiological Perspective. www.searo.who.int/.../Dengue_dengue-SEAR-2008.pdf 